\title{
Avaliação do desempenho de acadêmicos de odontologia no ensino superior sob metodologia ativa: percepções e vivências
}

\author{
Evaluation of dentistry academic performance in higher education under active methodology: \\ perceptions and experiences \\ Evaluación del desempeño académico de odontología en educación superior bajo metodología \\ activa: percepciones y experiencias
}

\section{Resumo}

A capacidade de adquirir conhecimento e habilidades no meio acadêmico é multifatorial, perpassando pela qualidade de ensino até empenho do acadêmico dentre outros indicadores, como aspectos sociais, familiares, institucionais e pedagógicos, que impactam diretamente no desempenho desse acadêmico em avaliações. Sabendo disso, a avaliação do desempenho acadêmico (ADA) é necessária para haja a compreensão se houve sedimentação do aprendizado e a percepção de qual processo avaliativo desenvolve melhor rendimento para os estudantes e como estes lidam com esse momento. Portanto, essa pesquisa objetivou apontar as percepções e vivências de acadêmicos do ensino superior em avaliação sob metodologia ativa e seu desempenho. Tratou-se de um estudo transversal e retrospectivo, com abordagem qualitativa desenvolvida através de formulário eletrônico, com 71 acadêmicos do curso de odontologia de uma Instituição de Ensino Superior, através de questões que abordavam os sintomas/sensações antes, durante e após a avaliação, e permitiam que estes escrevessem relatos dos pontos importantes da vivência. Ao analisar os sintomas/sensações relatados antes, durante e após a aplicação da metodologia ativa percebeu-se predominância das sensações de medo e palpitação antes da avaliação e, relaxamento e alívio após. Quanto aos fatores precipitantes de sintomas/sensações que interferiram no desempenho dos acadêmicos na avaliação sob metodologia ativa, a abordagem em aula do professor da disciplina, assim como os relatos de alunos que já haviam passado pela experiencia, estimularam o desenvolvimento de ansiedade e estresse. Já o preparo prévio e o formato avaliativo estimularam a tranquilidade e confiança. Conclui-se que a avaliação dos acadêmicos sob metodologia ativa pode trazer vivências positivas e conflitantes a este, contudo, a forma como o discente encara o processo interfere diretamente no seu desempenho.

Palavras-chave: Avaliação educacional; Métodos de avaliação; Ensino; Odontologia; Metodologia ativa.

\begin{abstract}
The ability to acquire knowledge and skills in the academic environment is multifactorial, ranging from the quality of teaching to the commitment of the academic among other indicators, such as social, family, institutional and pedagogical aspects, which directly impact the performance of this student in evaluations. Knowing this, the evaluation of academic performance (ADA) is necessary to understand if there was a sedimentation of learning and the perception of which evaluation process develops the best performance for students and how they deal with this moment. Therefore, this research aimed to point out the perceptions and experiences of academics of higher education in evaluation under active methodology and their performance. It was a cross-sectional and retrospective study, with a qualitative approach developed through an electronic form, with 71 students from the dentistry course of a Higher Education Institution, through questions that addressed the symptoms / sensations before, during and after the evaluation, and allowed them to write reports of the important points of the experience. When analyzing the symptoms / sensations reported before, during and after the application of the active methodology, a predominance of feelings of fear and palpitation was noticed before the evaluation and, relaxation and relief after. As for the precipitating factors of symptoms / sensations that interfered in the students' performance in the evaluation under active methodology, the classroom approach of the professor of the discipline, as well as the reports of students who had already gone through the experience, stimulated the development of anxiety and stress. The previous preparation
\end{abstract}


and the evaluation format stimulated tranquility and confidence. It is concluded that the evaluation of academics under active methodology can bring positive and conflicting experiences to this, however, the way the student sees the process directly interferes in their performance.

Keywords: Educational evaluation; Assessment methods; Teaching; Dentistry; Active methodology.

\section{Resumen}

La capacidad para adquirir conocimientos y habilidades en el ámbito académico es multifactorial, que va desde la calidad de la enseñanza hasta el compromiso del académico, entre otros indicadores, como aspectos sociales, familiares, institucionales y pedagógicos, que impactan directamente en el desempeño de este alumno. en evaluaciones. Sabiendo esto, la evaluación del desempeño académico (ADA) es necesaria para comprender si hubo una sedimentación de aprendizajes y la percepción de qué proceso de evaluación desarrolla el mejor desempeño de los estudiantes y cómo afrontan este momento. Por tanto, esta investigación tuvo como objetivo señalar las percepciones y experiencias de los académicos de la educación superior en la evaluación bajo metodología activa y su desempeño. Fue un estudio transversal y retrospectivo, con abordaje cualitativo desarrollado a través de un formulario electrónico, con 71 estudiantes de la carrera de Odontología de una Institución de Educación Superior, a través de preguntas que abordaron los síntomas / sensaciones antes, durante y después de la evaluación, y les permitió escribir informes de los puntos importantes de la experiencia. Al analizar los síntomas / sensaciones reportados antes, durante y después de la aplicación de la metodología activa, se notó un predominio de sentimientos de miedo y palpitaciones antes de la evaluación y relajación y alivio después. En cuanto a los factores precipitantes de síntomas / sensaciones que interfirieron en el desempeño de los estudiantes en la evaluación bajo metodología activa, el abordaje en clase del profesor de la disciplina, así como los relatos de los estudiantes que ya habían pasado por la experiencia, estimuló el desarrollo de ansiedad y estrés. La preparación previa y el formato de evaluación estimularon la tranquilidad y la confianza. Se concluye que la evaluación de académicos bajo metodología activa puede traer experiencias positivas y conflictivas a esto, sin embargo, la forma en que el estudiante ve el proceso interfiere directamente con su desempeño.

Palabras clave: Evaluación educativa; Métodos de evaluación; Ensenãnza; Odontología; Metodología activa.

\section{Introdução}

A capacidade de adquirir conhecimento e habilidades no meio acadêmico é multifatorial, perpassando pela qualidade de ensino até empenho do acadêmico dentre outros indicadores, como aspectos sociais, familiares, institucionais e pedagógicos (Vargas, 2014; Melguizo; Wainer, 2016) impactando diretamente no desempenho de universitários e na sua construção profissional (Barahona, 2014).

O desempenho desse acadêmico frente a nova rotina é influenciado por múltiplos fatores, tanto no dia a dia, quanto em momentos de avaliação. Até mesmo a idade dos indivíduos ao ingressar no meio acadêmico pode recair sobre seu desempenho, visto que os ingressantes adentram no ensino superior mais jovens, com idade média de 21 anos (Brasil, 2016), fato que implica em um amadurecimento cada vez mais cedo ou, muitas vezes, desencadeando sintomas de estresse e ansiedade pela não adaptação aquele novo ambiente, rotinas e demandas, podendo ainda contribuir para instabilidades psicossociais (Ramis; Mielke; Habeyche et al, 2012), caracterizando mais um fator a considerar.

E ainda, levando em consideração que a avaliação do desempenho acadêmico (ADA) é necessária para compreensão se houve sedimentação do aprendizado, a percepção de qual processo avaliativo desenvolve melhor rendimento para os estudantes ou ainda, resultados mais fidedignos, pode nortear docentes e gestores na busca de métodos mais justos e competentes para avaliação do conhecimento.

Definir desempenho acadêmico (DA) não é algo simples, visto que envolve a presença de ação frente a resultados, muitas vezes quantificados em notas, dependendo tanto de fatores individuais e intrínsecos, quanto de fatores externos, envolvendo a prática pedagógica e método avaliativo do docente (Munhoz, 2004; Nogueira; Costa; Takamatsu et al, 2013). Então, a escolha de metodologias que auxiliem o processo avaliativo pode ser uma ferramenta de auxílio ao trabalho do docente, assim como pode despertar autonomia nos discentes, como é o caso das avaliações por metodologia ativa.

A avaliação sob metodologia ativa tem como propósito fugir do aspecto somativo, possibilitando a formulação de uma avaliação formativa. Quando esta acontece, pode propor ao acadêmico uma possibilidade de reorganização de seus conhecimentos e aprendizado, ou ainda, direcionar para os propósitos ainda não atingidos no decorrer do processo de ensino, 
demonstrando a contínua e ininterrupta relação entre o ensinar e o aprender, podendo este ser comprovados através da avaliação mediado pelo professor que identifica as dificuldades, erros e acertos, ajudando no redirecionamento (Fernandes, 2010).

A dificuldades e questionamentos em avaliação não se esgotam em aplicação e atribuição de notas. Vão desde a escolha da metodologia correta para esta avaliação até a descoberta do real do papel do docente nesse processo. Há a dificuldade em associar os tópicos objetivo, conteúdo e métodos as expectativas das IES, além da adequação deste ao projeto pedagógico utilizado (Chaves, 2003).

Tendo em vista que o DA em avaliações depende tanto de fatores endógenos (aqueles relacionados ao próprio aluno), quanto os fatores exógenos (quando relacionados à instituição e ao corpo docente) (Guney, 2009), faz-se necessário conhecer com os discentes reagem aos processos avaliativos, possibilitando a administração destes. Portanto, essa pesquisa objetivou apontar as percepções e vivências de acadêmicos do ensino superior em avaliação sob metodologia ativa e seu desempenho.

\section{Referencial Teórico}

\subsection{Avaliação no Ensino Superior}

A avaliação é um processo delicado e instigante, independentemente do nível de ensino em que seja realizada. No Ensino Superior, o contexto de maior complexidade causa controvérsia, principalmente quanto aos motivos de sua aplicação. São variadas as suas formas de aplicação, sejam estas em forma de teste, através de textos dissertativos, ou apresentações, em um momento de avaliação, há a tentativa de mensuração do conhecimento e conduta de um indivíduo (Galocha; Poleto e Tavares, 2017).

A avaliação em si não pode servir apenas para obtenção de notas ou certificação, tendo proposito também de orientação e ponto de partida para planejamento de trabalho entre aluno e professor, permitindo que os resultados sejam analisados como ferramentas para identificação de dificuldades, além de oportunizar a organização de metas e conteúdo (Barbosa, 2008).

De acordo com Melo e Urbanetz (2008), a avaliação não se caracteriza como processo isolado, visto que o acadêmico deve ser avaliado em sua completude, além de possibilitar a observação das características criativas e seu processo evolutivo no decorrer do avanço no aprendizado, devendo haver coerência entre o que é ensinado em sala de aula e o que é testado em momento de avaliação, desestimulando a sensação de punição que pode vir atrelado ao momento avaliativo. Suhr (2012) complementa que o processo avaliativo deve estar diretamente relacionado aos objetivos a que se propõe, ou ainda, quando existe a necessidade da tomada de uma decisão, a avaliação se faz sempre presente e necessária.

Segundo Galocha; Poleto e Tavares (2017), o acadêmico ao chegar no ensino superior, quando submetido a uma avaliação pode não compreender a forma de utilização dessa ferramenta e, geralmente, pode dificultar o uso do recurso prejudicando os resultados, tomando como justificativa para a atitude, a conduta do professor. Nesse caso, está presente a sensação de que o instrumento não tem o propósito de realmente avaliar, mensurar um conhecimento adquirido nas aulas, mas sim modificar o motivo da avaliação.

Segundo Valmorbida e colaboradores (2014) a avaliação precisa considerar as características institucionais, os limites de conhecimento, a percepção dos avaliados, de forma que se atenda a necessidade de mensuração do conhecimento para obtenção de indicadores representativos de um universo global.

\section{Metodologia}

Este estudo é caracterizado como transversal, descritivo com abordagem qualitativa. De acordo com Lakatos e Marconi (2017), no método transversal o pesquisador possui como meta a formulação de questões ou de um problema com três 
possíveis fins: desenvolver hipóteses; aumentar a familiaridade do pesquisador com um ambiente, fato ou fenômeno, para realização de uma pesquisa futura mais precisa; ou modificar e classificar conceitos, tratando-se de um estudo exploratório.

Já de acordo com Sousa, Driessnack e Mendes (2007), os estudos descritivos ou exploratórios são usados quando o pesquisador observa, descreve e documenta vários aspectos do fenômeno. Não há manipulação de variáveis ou procura pela causa e efeito relacionados ao fenômeno. Desenhos descritivos descrevem o que existe de fato, determinam a frequência em que este fato ocorre e categoriza a informação. Fontelles e colaboradores (2009) complementam apresentando que nas abordagens qualitativas há a descrição das relações entre o objetivo e o resultado, com a análise da subjetividade e individualidade dos fenômenos.

O estudo em questão foi desenvolvido através de um Formulário Eletrônico através do Google Formes conduzido de forma remota no mês de novembro de 2020.

A população deste estudo foi composta pelos acadêmicos de Odontologia de uma Instituição de Ensino Superior, sendo a amostra selecionada por amostragem intencional, formada pelos discentes que possuíam o status aprovado na disciplina de "Estágio Supervisionado em Clínica Integrada 1 (ESCI1)" e tivessem cumprido a disciplina nos semestres de 2019.1 e 2019.2 .

Foram inclusos na pesquisa, os acadêmicos que, após convite via email, redes sociais e aplicativos de conversação, concordassem em participar da pesquisa acessando o formulário proposto pelos pesquisadores. Contudo, foram exclusos da pesquisa, discentes que acessassem o formulário após o prazo determinado para a coleta, que respondessem de forma incompleta o formulário proposto, ou ainda, que desistisse da participação após seu início.

Inicialmente, foi realizado o convite para a participação na pesquisa às turmas do curso de odontologia que estivessem de acordo com os critérios de elegibilidade. Após a manifestação do interesse, o link do formulário eletrônico foi enviado ao participante via e-mails, redes sociais e aplicativos de conversação, e estes tiveram a possibilidade de acessar o formulário no período de um mês (das 00:00hs de 14 de outubro a 23:59hs de 14 de novembro de 2020).

Inicialmente o formulário apresentava perguntas para a identificação do participante para coleta de informações como sexo, idade, cor, religião, se realiza atividade laboral, consumo de drogas lícitas terapêuticas, forma de financiamento estudantil e horas de dedicação ao estudo nos períodos.

Em seguida, trazia questões em que o acadêmico podia apontar sensações que pode ter sentido antes, durante e após a avaliação sob metodologia ativa, além de conter perguntas em que o participante poderia discursar sobre quais fatores o influenciavam a sentir ansiedade, estresse, tranquilidade ou calma na avaliação.

Vale salientar que a disciplina escolhida para a realização da pesquisa tem a introdução das práticas cirúrgicas e anestésicas, operacionais do profissional odontólogo. As avaliações na mesma são desenvolvidas através da metodologia de Gincana, onde acontece a simulação de caso e onde cada discente irá desenvolver a sua prática mediante a simulação de um caso clínico, seguindo com avaliação prática de demonstração de habilidades com arguição oral pelos professores da disciplina.

O trabalho foi submetido ao Comitê de Ética e Pesquisa (CEP) do Centro Universitário Leão Sampaio obtendo o parecer de aprovado com $\mathrm{n}^{\circ} 4.480 .537$. Todos os participantes foram informados dos procedimentos a serem adotados na pesquisa, sendo convidados a conhecer o Termo de Consentimento Livre e Esclarecido (TCLE) e assinar de forma virtual o Termo de Consentimento Pós Esclarecido (TCPE) conforme previsto pelas resoluções 466/12 e 510/16 do Conselho Nacional de Saúde.

Os dados obtidos na pesquisa foram transferidos para o software Microsoft Excel® 360 e, em seguida, foram analisados inicialmente pelo software estatístico JASP, versão 0.14, para obtenção de estatísticas descritivas.

Em seguida, os relatos apresentados pelos participantes foram categorizados em pontos chave e, as transcrições 
copiadas igualmente constava no formulário, para embasar os pontos chave quando necessários. Para manter o anonimato dos participantes da pesquisa, assim como suas respostas, estes foram enumerados (n.01, n.03, ..., n.23) para manutenção do sigilo.

Quanto aos sentimentos/sensações relatados nos diferentes momentos pesquisados, foi analisada a frequência de aparecimento deste antes, durante e após a metodologia de gincana. Em seguida, foram criadas nuvens de palavras através da página https://www.wordclouds.com, onde cria-se uma proporção de tamanho das palavras com a frequência de aparecimento na pesquisa.

\section{Resultados e Discussão}

Participaram do estudo 71 acadêmicos, em sua maioria do sexo feminino (59,15\%), sendo 40,85\% do sexo feminino. Quando a frequência das demais variáveis, percebeu-se maior número de indivíduos com idade entre 18 a 24 anos (74,65\%), de cor parda $(50,70 \%)$, que não desempenham função laboral $(80,28 \%)$, que não haviam feito uso de droga terapêutica como sedativo ou calmante $(70,42 \%)$, possuindo o curso custeado por bolsas e financiamentos $(84,51 \%)$, relatando estudar entre $1 \mathrm{e}$ 3 horas por dia $(42,25 \%)$, como pode ser observado na Tabela 1.

Tabela 1 - Caracterização da amostra estudada.

\begin{tabular}{lll}
\hline Variável & $\mathrm{n}(71)$ & $\%$ \\
\hline Sexo & & \\
Feminino & 42 & $59,15 \%$ \\
$\begin{array}{l}\text { Masculino } \\
\text { Idade }\end{array}$ & 29 & $40,85 \%$ \\
18 a 24 anos & 53 & $74,65 \%$ \\
25 a 30 anos & 11 & $15,49 \%$ \\
31 a 35 anos & 2 & $2,82 \%$ \\
Acima de 35 anos & 5 & $7,04 \%$ \\
Cor & & \\
Branco & 30 & $42,25 \%$ \\
$\begin{array}{l}\text { Pardo } \\
\text { Preto }\end{array}$ & 36 & $50,70 \%$ \\
Outras & 2 & $2,82 \%$ \\
Função Laboral & 3 & $4,23 \%$ \\
Trabalha & & \\
Não trabalha & 14 & $19,72 \%$ \\
Uso de & & \\
terapêutica & 57 & $80,28 \%$ \\
Sim & & \\
Não & & \\
Custeio do Curso & & \\
Bolsas/Financiamento & 60 & $84,51 \%$ \\
Próprio & 11 & $15,49 \%$ \\
Horas de Estudo & & \\
Até 1 hora & 13 & $18,31 \%$ \\
De 1 a 3 horas & 30 & $42,25 \%$ \\
$\begin{array}{l}\text { De 3 a 5 horas } \\
\text { Mais de 5 horas }\end{array}$ & 19 & $26,76 \%$ \\
\hline$\quad 9$ & $12,68 \%$ \\
\hline
\end{tabular}

Fonte: Dados da Pesquisa (2021). 
Ao analisar as sensações e sentimentos relatados antes, durante e após a aplicação da metodologia ativa de gincana pelos acadêmicos, com foco nas temáticas de cirurgia bucal e anestesiologia, percebeu-se padrão semelhante de relatos nas duas temáticas em dois dos três momentos avaliados, com predominância das sensações de medo e palpitação antes da avaliação e, relaxamento e alívio após. Durante a avaliação houve predomínio do relato palpitação e medo, porém, com maior citação na temática de cirurgia bucal. Os relatos dos acadêmicos podem ser visualizados através da Figura 1.

Figura 1 - Relação de sensações e sentimentos relatados pelos acadêmicos antes, durante e após a metodologia de gincana com as temáticas de cirurgia bucal e anestesiologia.
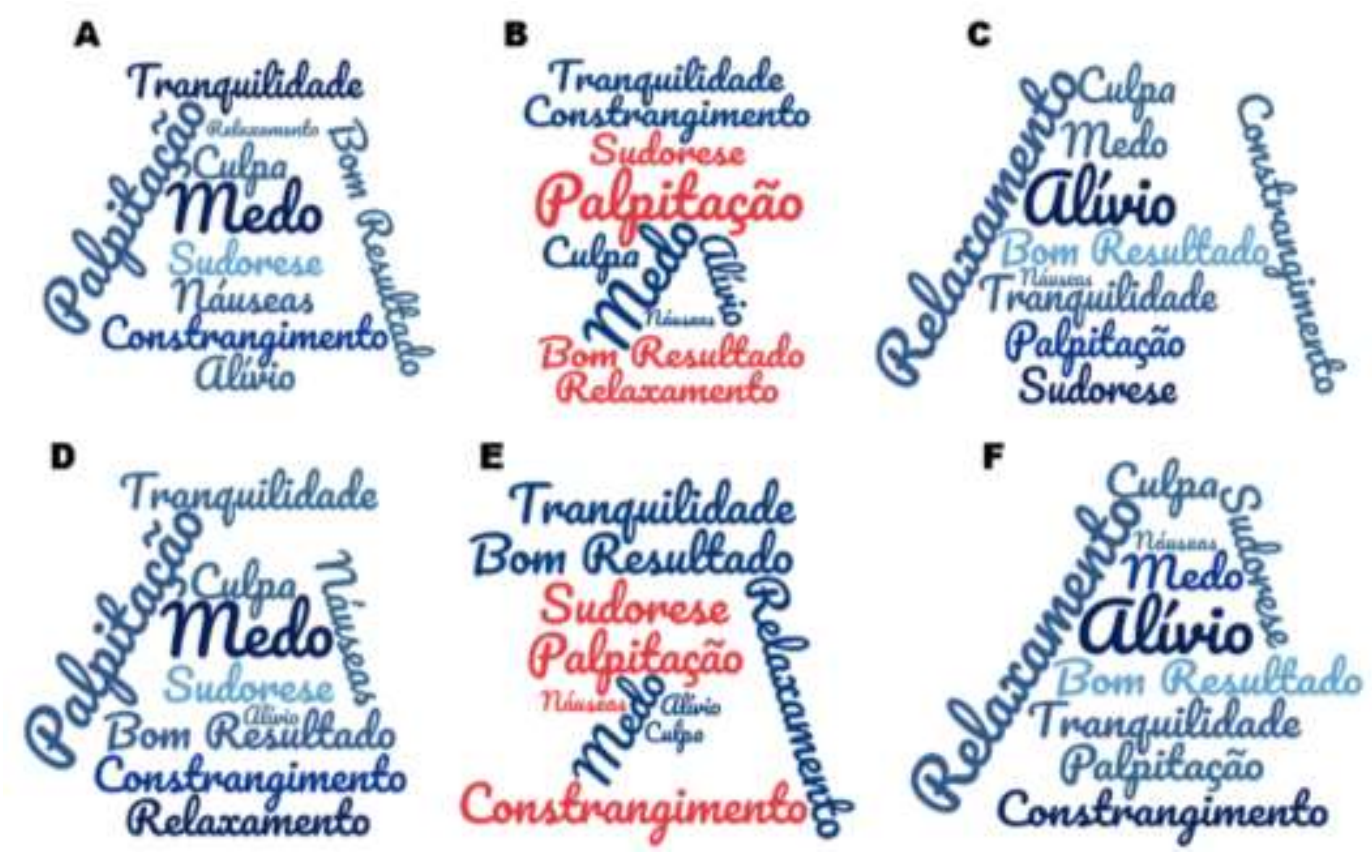

*(A, B , C ) - Sensações e sentimentos antes (A), Durante (B) e após (C) metodologia de gincana respectivamente, com a temática de Cirurgia Bucal. (D, E, F). Sensações e sentimentos antes (D), Durante (E) e após (F) metodologia de gincana respectivamente, com a temática de Anestesiologia.

Fonte: Dados da Pesquisa (2021).

A presença de nervosismo, ansiedade e estresse durante avaliações é comum e frequente em avaliações (Fragelli, 2015; Fragelli; Fragelli, 2017) trazendo consigo todas as alterações fisiológicas destes como sensação de aperto no peito, palpitação, medo e angústia (MacGeorge; Samter \& Gillihan, 2005). Contudo, a presença de apoio familiar e docente, a atitude otimista, juntamente com sensação de confiança podem estimular o desempenho positivo do acadêmico (Besa Gutiérrez; Gil Flores e González, 2019).

Deve-se sempre considerar o momento avaliativo complexo, envolvendo fatores culturais, emocionais teorias e princípio. Sabe-se também que docente e discente devem construir o momento de forma conjunta, não apenas levando em consideração as experiências do professor, mas também do aluno, uma vez que estes trazem lembranças e conceitos do processo avaliativo e, alguns desses negativos, desencadeando sintomas fisiológicos e psicológicos negativos (Duarte; Melo; Morais Cardoso et al, 2020; Tomaschewski-Barlem; Lunardi; Ramos et al, 2013).

Ao serem abordados os fatores precipitantes de sintomas/sensações que interferiram no desempenho dos acadêmicos na avaliação sob metodologia de gincana, houve a categorização das respostas em tópicos como "estimularam estresse e ansiedade", "estimularam tranquilidade e confiança" e, "interferiram como fatores externos", como pode ser identificado no Quadro 1. 
Quadro 1 - Fatores apontados pelos acadêmicos como causadores de sintomas/sensações que interferiram em seu desempenho acadêmico na modalidade de gincana.

\begin{tabular}{|l|l|l|}
\hline \multicolumn{1}{|c|}{ Estresse e Ansiedade } & Tranquilidade e Confiança & Fator Externos \\
\hline$\bullet$ Quantidade de Conteúdo & $\bullet$ Incentivo do professor & $\bullet$ Relacionamento amoroso \\
- Pouco Tempo & $\bullet$ Estudo prévio & $\bullet$ Problemas do dia a dia \\
- Abordagem do Professor & $\bullet$ Música antes da prova & $\bullet$ Relacionamento com o pai \\
- Pressão Imposta & $\bullet$ Treinar antes & $\bullet$ Rorte de familiar \\
- A Espera para realizar a prova & $\bullet$ Resultado imediato & $\bullet$ Responsabilidade doméstica \\
- A metodologia & $\bullet$ Presença e participação nas aulas & \\
- Relato dos colegas dos semestres a frente & $\bullet$ Autocontrole & \\
- Insegurança & & \\
- Sedo & & \\
- Falta de Empatia & & \\
- Cobrança pessoal & & \\
\hline
\end{tabular}

Fonte: Dados da Pesquisa (2021).

Quanto aos fatores que estimularam o desenvolvimento de ansiedade e estresse durante avaliação, a abordagem desempenhada pelo professor da disciplina, assim como os relatos de alunos que já haviam passado pela experiencia de avaliação por metodologia de gincana, receberam destaque nos relatos como estes:

“...Alguns professores incitam os alunos pra que eles se dediquem mais, a ponto de dizer que ninguém tira 10... Mas vejo como incentivo para se superar, acredito que outros alunos não consigam ver de mesma maneira, e se sintam mais pressionados" (n.24)

“..., a abordagem do professor foi fundamental para tranquilizar o meu estado emocional” (n. 53)

“...Ansiedade, por ser algo novo, e relato de colegas de semestres superiores fez com que ficasse nervoso durante toda a prova". (n.18)

Para Luckesi (2005), o docente é agente atuante do processo avaliativo, sendo o objetivo deste a melhora da aprendizagem do estudante e, para alcançá-lo, o professor deve contribuir na escolha do instrumento adequado e diversificado, tornando a avaliação "um ato dialógico" em que este atua e colabora com a construção.

Pascon, Otrenti e Mira (2018) complementam a fala de Luckesi ao apresentarem que, para que haja um bom engajamento e riqueza no processo avaliativo, se faz necessário que os discentes e docentes estejam aptos para implementação desse processo ativo de ensino-aprendizagem, uma vez que os modelos avaliativos também podem fazer parte do processo de formação dos estudantes. No entanto, ainda se encontra distante essa realidade.

Hirsch e colaboradores (2018) reforçam que o bom relacionamento com o professor durante avaliações e no decorrer do curso mostra-se como fundamental para o bom desenvolvimento do aluno. A falta de tal, comporta-se como variante estressora para o ambiente acadêmico, diminuindo o aprendizado, engajamento e contribuindo para o sentimento de incapacidade por parte dos discentes e pensamentos de desistência do curso (Tomaschewski-Barlem et al, 2013).

Já quanto ao estímulo da tranquilidade e confiança, os acadêmicos percebem a importância do preparo prévio, da criação de seus próprios rituais de preparação, ou mesmo, o formato avaliativo, como é possível notar nas falas abaixo: 
“... Domínio do Tema, ou quando vou bem nas práticas, escutar música antes. É quando eu consigo focar no momento e não no resultado". (n.12)

"...Após a gincana, o fato de o professor avaliar e dar a nota na hora de certa forma gera uma tranquilidade, você não fica preocupado sobre quanto vai tirar. Treinar antes da gincana nas aulas também gera uma certa confiança". (n.16)

"Sim! Dominar antes o assunto, the dá autoconfiança e tranquilidade na hora de realizar qualquer avaliação, apesar de saber que você está sendo avaliado já the deixa um pouco nervoso. Se você esquecer que é uma avaliação e começar a pensar que é um momento em que você está apenas demostrando o seu conhecimento, talvez você se sinta mais calmo e tenha maior capacidade de realizar tal demonstração." (n.24)

O emprego de metodologias ativas no ambiente acadêmico traz o discente para o "palco" de seu próprio aprendizado, gerando autonomia e responsabilidade na gestão dos processos e avaliações, permitindo maior troca e diálogo entre docente e discentes, desenvolvimento de habilidades e competências ímpares para seu futuro profissional (DIAS-LIMA et al., 2019).

De acordo com Oenning e Oliveira (2011), ao optar por métodos avaliativos mais dinâmicos e intuitivos, o docente proporciona uma nova vivencia do aprendizado para o acadêmico, minimizando possíveis prejuízos que este possa vir a ter por estar sendo avaliado.

Um dos desafios inerentes a esse processo avaliativo e utilização das metodologias ativas consiste na dificuldade de adaptação de alguns alunos a esses métodos e a falta de habilidade destes para irem em busca do próprio aprendizado. Além disso, características pessoais ou agentes externos podem tornar esse processo mais desafiador, portanto se faz necessário também a diversificação dos instrumentos avaliativos e dos modelos de aprendizagem para que atendam às necessidades de todos (Dias-Lima; Silva; Ribeiro et al, 2019).

De acordo com Silva e colaboradores (2015), fatores intrínsecos podem influenciar no desempenho do acadêmico frente uma avaliação, como dedicação exclusiva ao estudo e participação em atividades extraclasse. Polesi (2017) complementa com seu estudo com 112 acadêmicos de uma IES no estado do Paraná, onde aponta que a presença da característica de autocontrole no acadêmico, influencia na melhor tomada de decisão e o leva a obter melhor rendimento.

Oliveira e colaboradores (2020) também apontam atitudes pessoais como influentes no bom rendimento acadêmico ao analisar 262 acadêmicos de fisioterapia de uma IES do Ceará, percebendo que um maior número de horas dedicadas ao estudo, assim como acompanhamento frequente às aulas e participação em atividades extracurriculares, contribui para uma melhor percepção de rendimento acadêmico.

Fatores externos também podem interferir, não somente em avaliações sob metodologias ativas, como também em todo desempenho acadêmico. Falas como as desenvolvidas abaixo podem identificar esse fato:

"No momento não tem nada que posso destacar, porém, já houve momentos em que tive perda de familiares que me deixa com dificuldade de me concentrar e aprender as disciplinas e principalmente desenvolver as atividades acadêmicas. Ah, dificuldades financeiras também podem influenciar na perda do desempenho já que, se reprovar, posso perder meu fies, ou porque o curso precisa de alguns materiais caros, e se a gente não tem, fica prejudicado nas práticas. Ou mesmo quando não consegue adquirir todo o material a tempo das aulas seja por questão financeira, seja por uma questão de logística" (n.24). 
O custeio das atividades acadêmicas, os gastos com materiais necessários à prática também são questões que podem trazer estresse e preocupação aos acadêmicos em momentos de prova. Neste estudo, a maioria dos acadêmicos $(84,5 \%)$ custeiam a faculdade através de bolsas de estudo fornecidas por programas federais (ProUni) ou municipais (Bolsa Social), ou ainda, financiam seus estudos através de Financiamentos Estudantis (FiEs), o que lhes traz uma "pressão" a mais ao realizar as avaliações, como visto no trecho acima.

Tal discurso é também observado nos estudos de Ferreira (2015) e Rodrigues e colaboradores (2016), contudo os autores apresentam o fato de ter bolsa ou financiamento como fator de influência positiva ao desempenho acadêmico, quando comparam ao DA de acadêmicos que custeiam a própria faculdade, fenômeno que possa ter alguma relação com os achados deste estudo, uma vez que assim como a maioria dos acadêmicos conta com bolsas e financiamentos para custeio da faculdade, a mesma maioria também apresenta desempenho satisfatório.

Ao passo que ter a faculdade custeada por financiamentos pode impactar no rendimento e perspectiva de aprovação na disciplina, outro fator importante que interfere no desempenho dos estudantes é o fato de alguns apresentarem vínculos empregatícios no decorrer dos anos de formação, muitas vezes atribuídas às necessidades destes de custearem a formação, levando-os a lidar com uma maior demanda de atividades. O cansaço, o menor tempo disponível para dedicar-se aos estudos e a falta de motivação decorrentes do excesso de responsabilidades podem assim dificultarem a aprendizagem e, consequentemente, fazer com que esses estudantes apresentem uma redução do rendimento acadêmico (Paula Langame; Neto; Melo et al, 2016; Vargas; Paula, 2013).

Corroborando com relatos dos participantes da atual pesquisa, o estudo de Lopes, Sousa e Santos (2020) mostra que dificuldades financeiras se apresentam como uma variável de destaque na influência do desempenho educacional na medida em que dificultam o acesso a materiais para estudo e até mesmo ao transporte à universidade.

Desta forma, os financiamentos e bolsas acadêmicas têm a tendência de ser uma oportunidade aos alunos, com menor estrutura e renda familiar, para suprirem os custos da formação e assim obterem um desempenho acadêmico satisfatório.

Ainda, quanto a percepção do próprio desempenho, os acadêmicos desta pesquisa apontam que, em sua maioria, avaliam este como bom ou ótimo (47,89\% e 26,76\% respectivamente), como mostra o Gráfico 1 . Tal percepção pode aparentar uma boa adequação da aplicação da metodologia ativa em gincana como instrumento avaliativo para os discentes.

Gráfico 1 - Autopercepção do desempenho dos acadêmicos na avaliação sob a metodologia de gincana.

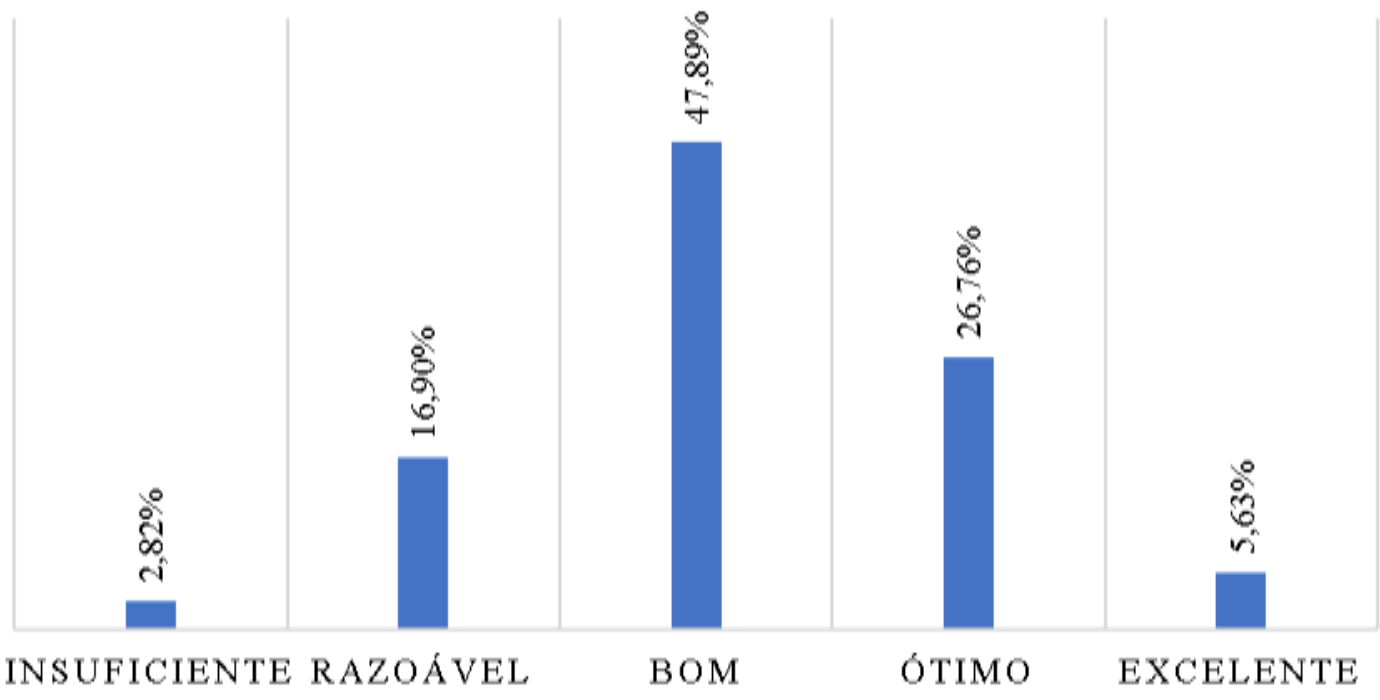

Fonte: Dados da Pesquisa (2021). 
Pode-se então apontar a avaliação por metodologia ativa como uma possível ferramenta para obtenção de um desempenho satisfatório por parte dos acadêmicos, de forma que traga engajamento destes no processo de ensino e aprendizado, melhorando o diálogo docente-discente, assim como o aprendizado e a experiencia de ambos.

\section{Considerações Finais}

Este estudo evidenciou que, em momentos de avaliação, pode haver sensações desconfortáveis ao acadêmico, por este se sentir intimidado. Contudo, após o término da avaliação, a situação tende a se estabilizar. Os próprios discentes encaram o treino prévio, o estudo constante e o apoio dos docentes como fatores que podem influenciar para que seu desempenho seja positivo.

Conclui-se, portanto, que a avaliação dos acadêmicos sob metodologia ativa pode trazer vivências positivas e conflitantes a este, contudo, a forma como o discente encara o processo interfere diretamente no seu desempenho. No entanto, estima-se que novas pesquisas sejam realizadas para constatação de resultados mais fidedignos, com populações maiores de estudantes, assim como a comparação das percepções dos acadêmicos sob metodologias diferentes.

\section{Agradecimentos}

Esta pesquisa só foi possível graças ao apoio do Centro Universitário Dr. Leão Sampaio, que incentiva à pesquisa cientifica e o aprimoramento de seus docentes.

\section{Referências}

Barahona, P. (2014). Factores determinantes del rendimiento académico de los estudiantes de la Universidad de Atacama. Estudios pedagógicos (Valdivia), 40(1), 25-39.

Barbosa, J. R. A. (2008). A avaliação da aprendizagem como processo interativo: um desafio para o educador. Faetec.

De Besa Gutiérrez, M. R., Gil Flores, J., \& García González, A. J. (2019). Variables psicosociales y rendimiento académico asociados al optimismo en estudiantes universitarios españoles de nuevo ingreso.

Brasil. (2016). Instituto Nacional de Pesquisas Educacionais. Sinopse Estatística da Educação Superior. <http://inep.gov.br/web/guest/sinopses-estatisticas-daeducacao-superior>.

Chaves, S. M. (2003). Avaliação da aprendizagem no ensino superior: realidade, complexidade e possibilidades. Universidade de São Paulo.

Dias-Lima, A., Silva, M. D. C., Ribeiro, L. C. V., Bendicho, M. T., Guedes, H. T. V., \& Lemaire, D. C. (2019). Avaliação, ensinagem e metodologias ativas: uma experiência vivenciada no componente curricular Mecanismos de Agressão e de Defesa, no curso de Medicina da Universidade do Estado da Bahia, Brasil. Revista Brasileira de Educação Médica, 43(2), 216-224.

Duarte, S. J., de Melo, C. R. C., de Morais Cardoso, M. Â., \& de Souza Gonçalves, A. (2020). Olhar dos acadêmicos do ensino superior para mudanças nas avaliações. Humanidades e tecnologia (FINOM), 23(1), 149-162.

Fernandes, C. (2010). Dimensões da Avaliação. Concepções e finalidades da avaliação em educação. Avaliação: Um Tema Polêmico. Um Salto para o Futuro, TV Escola, Boletim 18, 2010.

Ferreira, M. A. (2015). Determinantes do desempenho discente no ENADE em cursos de Ciências Contábeis.

Fontelles, M. J., Simões, M. G., Farias, S. H., \& Fontelles, R. G. S. (2009). Metodologia da pesquisa científica: diretrizes para a elaboração de um protocolo de pesquisa. Revista paraense de medicina, 23(3), 1-8.

Fragelli, R. R. (2015). Trezentos: Aprendizagem colaborativa como uma alternativa ao problema da ansiedade em provas. Revista Eletrônica Gestão \& Saúde Brasília, (6), 860-872.

Fragelli, R. R., \& Fragelli, T. B. O. (2017). Three Hundred: the human dimension of the method. Educar em Revista, (63), 253-265.

Galocha, C., Poleto, S. S., \& Tavares, M. (2017). Avaliação no ensino superior: paradoxos e desafios. Revista Ambiente Educação, $10(1), 25-35$.

Guney, Y. (2009). Exogenous and endogenous factors influencing students' performance in undergraduate accounting modules. Accounting Education, 18(1), 51-73.

Hirsch, C. D., Barlem, E. L. D., Almeida, L. K. D., Tomaschewski-Barlem, J. G., Lunardi, V. L., \& Ramos, A. M. (2018). Fatores percebidos pelos acadêmicos de enfermagem como desencadeadores do estresse no ambiente formativo. Texto \& Contexto-Enfermagem, 27(1). 
Marconi, M. D. A., \& Lakatos, E. M. (2017). Fundamentos de metodologia científica. (8a ed.), Atlas.

Lopes, J. M. R., Sousa, L., \& Santos, M. (2020). Fatores associados ao desempenho acadêmico de estudantes de licenciatura em Educação Física do Ceará no ENADE. Revista Educação \& Linguagem, 7, 62-74.

Luckesi, C. C. (2005). Avaliação da aprendizagem na escola: reelaborando conceitos e recriando a prática. In Avaliação da aprendizagem na escola: reelaborando conceitos e recriando a prática (pp. 115-115).

MacGeorge, E. L., Samter, W., \& Gillihan, S. J. (2005). Academic stress, supportive communication, and health. Communication Education, 54(4), 365-372.

Melguizo, T., \& Wainer, J. (2016). Toward a set of measures of student learning outcomes in higher education: evidence from Brazil. Higher Education, 72(3), 381-401.

Melo, A.; \& Urbanetz, T. S. (2008). Fundamentos da Didática:Curitiba: Ibpex.

Munhoz, A. M. H. (2004). Uma análise multidiciplinar da relação entre inteligencia e desempenho academico em universitarios ingressantes.

Nogueira, D. R., da Costa, J. M., Takamatsu, R. T., \& dos Reis, L. G. (2013). Fatores que impactam o desempenho acadêmico: uma análise com discentes do curso de ciências contábeis no ensino presencial. Revista de Informação Contábil, 7(3), 51-62.

Oenning, V., \& Oliveira, J. M. P. (2011). Dinâmicas em sala de aula: envolvendo os alunos no processo de ensino, exemplo com os mecanismos de transporte da membrana plasmática. Revista de Ensino de Bioquímica, 9(1), 18-29.

Oliveira, T. M., de Lima Santos, F. A., de Lima, W. P., Bezerra, M. A. A., dos Santos Camurça, A. J., de Lavor Farias, E., \& Neto, I. C. P. (2020). Percepção de acadêmicos sobre a relação entre a participação em grupos de estudo e rendimento em avaliações. Research, Society and Development, 9(12), e15091211027-e15091211027.

Paula Langame, A., Neto, J. A. C., Melo, L. N. B., Castelano, M. L., Cunha, M., \& Ferreira, R. E. (2016). Qualidade de vida do estudante universitário e o rendimento acadêmico. Revista brasileira em Promoção da Saúde, 29(3), 313-325.

Pascon, D. M., Otrenti, E., \& Mira, V. L. (2018). Percepção e desempenho de graduandos de enfermagem em avaliação de metodologias ativas. Acta Paulista de Enfermagem, 31(1), 61-70.

Polese, A. G. (2017). Determinantes do desempenho acadêmico na área de negócios: uma análise de variáveis comportamentais (Bachelor's thesis, Universidade Tecnológica Federal do Paraná).

Ramis, T. R., Mielke, G. I., Habeyche, E. C., Oliz, M. M., Azevedo, M. R., \& Hallal, P. C. (2012). Smoking and alcohol consumption among university students: prevalence and associated factors. Revista Brasileira de Epidemiologia, 15(2), 376-385.

Rodrigues, B. C.O., Resende, M. S., Miranda, G. J., \& Pereira, J. M. (2016). Determinantes do desempenho acadêmico dos alunos dos cursos de ciências contábeis no ensino a distância. Enfoque: Reflexão Contábil, 35(2), 139-153.

Silva, V. D., Oliveira, K. D., Rogers, P., \& Miranda, G. J. (2015). Comportamento e desempenho acadêmico no curso de ciências contábeis. In IX Congresso Anpcont (pp. 1-16).

Sousa, V. D., Driessnack, M \& Mendes, I. A. C. (2007). Revisão dos desenhos de pesquisa relevantes para enfermagem: parte 2: desenhos de pesquisa qualitativa. Revista Latino-americana de enfermagem, 15(4), 684-688.

Suhr, I. R. F. (2012). Processo avaliativo no ensino superior. Editora Ibpex.

Tomaschewski-Barlem, J. G., Lunardi, V. L., Ramos, A. M., Silveira, R. S. D., Barlem, E. L. D., \& Ernandes, C. M. (2013). Manifestações da síndrome de burnout entre estudantes de graduação em enfermagem. Texto \& Contexto-Enfermagem, 22(3), 754-762.

Valmorbida, S. M. I., Ensslin, S. R., Ensslin, L., \& Ripoll-Feliu, V. M. (2014). Avaliação de desempenho para auxílio na gestão de universidades públicas: análise da literatura para identificação de oportunidades de pesquisas. Journal of Accounting, Management and Governance, 17(3).

Vargas, G. M. G. (2014). Factores asociados al rendimiento académico tomando en cuenta el nivel socioeconómico: Estudio de regresión múltiple en estudiantes universitarios. Revista Electrónica Educare, 18(1), 119-154.

Vargas, H. M., \& Paula, M. D. F. C. D. (2013). A inclusão do estudante-trabalhador e do trabalhador-estudante na educação superior: desafio público a ser enfrentado. Avaliação: Revista da Avaliação da Educação Superior, 18(2), 459-485. 